\title{
Game Theory and Environmental and Resource Economics-In Honour of Alfred Endres, Part Two
}

\author{
Michael Finus $^{1}$ - Bianca Rundshagen ${ }^{2}$
}

Published online: 16 August 2016

(C) Springer Science+Business Media Dordrecht 2016

In 2015, Part 1 of Game Theory and Environmental and Resource Economics in Honour of Alfred Endres was published in Volume 62, issue 4 in Environmental \& Resource Economics. This volume, Part 2, completes the special issue devoted to Alfred Endres on the occasion of his 65th birthday in 2015, as a tribute to his fundamental contributions to the field of environmental and resource economics. For an appreciation of Endres' vita and research achievements, we would like to refer the reader to the introduction in Part 1 (Finus and Rundshagen 2015). Moreover, the reader will find an overview of the contributed papers published in Part 1 and a general motivation of the topic of the special issue. In the following, we will give a short overview of the contributions that appear in Part 2.

As in Part 1, the first set of papers deals with the topic of international environmental economics and contains analyses of international environmental or fishery agreements as well as non-cooperative climate policy.

In the first paper, Caparrós (2016) surveys the game-theoretic literature which focuses on the negotiation process of international environmental agreements. The issues covered differ from those typically discussed on international environmental agreements, suggesting important avenues for future research. The paper discusses bargaining models which are extensions of the model of Rubinstein (1982) as well as other negotiation models. Issues investigated in the reviewed literature include, for instance, strategic behaviour in the context of asymmetric information, the role of delegation, group formation during the negotiation process, the impact of unilateral commitments or the influence of expected future bargaining processes on investment decisions. Caparrós discusses which negotiation-outcomes of selfinterested agents can be expected and demonstrates that even though the basic bargaining model is generally optimistic, most of the recent extensions of the basic model obtain rather pessimistic results.

Bianca Rundshagen

Bianca.Rundshagen@fernuni-hagen.de

1 Department of Economics, University of Bath, Bath, UK

2 Institute of Economic Theory, University of Hagen, Hagen, Germany 
The next two papers on global public good provision regard equity considerations and their effect on the stability and effectiveness of coalition formation. Vogt (2016) uses the stability concept of internal and external stability. He discusses the effects of inequality aversion on the equilibrium coalition structure in the context of asymmetric players. He allows players to be heterogeneous with respect to all model parameters including costs, benefits and inequality aversion. The model is applied to the context of climate mitigation and simulations are conducted with a version of the RICE model of Nordhaus, calibrated for twelve world regions. Vogt shows that with suitable transfer schemes, large coalitions with economically different countries are stable, whereas without transfers the maximum stable coalition size equals two, despite inequality aversion.

Buchholz et al. (2016) clarify the relationship between core stability, a classical stability concept of cooperative game theory, and equitable burden sharing. They consider the "Moulin sacrifice" as an equity norm, a utility measure, which is based on Moulin's (1987) egalitarian equivalence concept. They show that Pareto-optimal allocations which are not in the core can be blocked by those countries for which the public good contribution entails the highest burden according to the Moulin sacrifice. In contrast, if the burden is rather equally distributed between countries, a Pareto-optimal allocation belongs to the core. Through the link between the concept of the core and the Moulin sacrifice, the authors provide an additional normative motivation for the core concept.

Duscha and Ehrhart (2016) analyse the potential of no-lose targets to engage non-Annex I (NAI) countries in combating climate change. No-lose targets are described as follows: if emissions of NAI countries are lower than a predetermined target, which is chosen by a global social planner, the NAI can sell the corresponding number of permits. However, if emissions are higher than the target, for instance because of strong economic growth, there is no direct punishment but no permits can be sold. Thus, no-lose targets provide incentives to reduce emissions without neglecting the NAI countries' concerns about growth constraints under emission restrictions. The authors demonstrate that the application of no-lose targets for NAI countries decreases global emissions compared to the case where NAI-countries do not participate. A precondition for no-lose targets to make a meaningful contribution to global emission reduction are ambitious reduction targets for Annex I countries.

Nieminen et al. (2016) is the last paper in the first group of papers on international agreements. They consider a dynamic partition function game between Denmark, Poland and Sweden as neighbouring states in the Baltic Sea. Whereas in the fishery agreements literature coalition formation games usually are restricted to one fish species, the focus of this paper lies on the comparison of the scopes of cooperation between multispecies and single species agreements. In case of coalition formation with respect to a multispecies agreement, coalition partners coordinate their harvesting rates of the species cod, herring and sprat. In particular, they explicitly take biological interactions between the species into account, which is not the case in the single species agreement scenario. The authors show that considering multispecies linkages of Baltic Sea fisheries increases the scope of cooperation. Moreover, the paper touches on the issue of climate change. In particular, it is shown that the likelihood of a binding agreement in the Baltic Sea fisheries may increase due to higher gains from cooperation if the impact of climate change is considered in the formation of agreements.

Karp et al. (2016) study a non-cooperative dynamic game between three agents: a large bloc of fossil fuel exporters, a large bloc of fuel importers and a third non-strategic bloc composed of emerging and developing countries. The importer bloc as well as the bloc of non-strategic agents are assumed to suffer from environmental damages, whose level depends on the global pollution stock, which in turn depends on the equilibrium level of fossil fuel consumption. The exporter bloc as well as the importer bloc use trade policy to improve 
their terms of trade. Additionally, the strategic importer bloc uses trade policy to control future damages, however without internalizing the damages suffered by the non-strategic bloc. Using numerical simulations, the authors show that taxes dominate quota policies for importers as well as for exporters, which is also beneficial for the fringe due to less climate damages.

The paper by Currarini et al. (2016) considers the linkages between network economics and environmental and resource economics. It sets out with an introduction to network theory, a rather new and recent topic in the context of environmental and resource economics. The introduction is an excellent piece which is very useful for all those with no or little background in network economics. In the second part of the paper, possible applications in the environmental and resource economics context are highlighted and discussed. This comprises the formation of international environmental coalitions as well as diffusion of green technologies, and the use and collective management of natural resources. For each of these and further applications, the authors either briefly review the corresponding literature or explain how the use of network economics as an analytical tool could provide valuable insights in future research. It appears that the application of network economics to environmental and resource issues is just in its infancy and that new avenues of research need to be explored.

The subsequent papers deal with the interactions among market participants and interactions between market participants and an environmental regulator.

Dasgupta et al. (2016) pay attention to the demand side of goods whose consumption generates environmental damages. The authors link behavioural economic approaches, with strong reference to concepts from sociology and psychology, with traditional consumer theory. They discuss optimal environmental policy in the context of interdependent consumer preferences and outline some of their recent work and ideas within a general framework. Two kinds of interdependent preferences are distinguished: socially-embedded preferences, where a consumer is concerned about how his consumption level relates to the average of a reference group, and socially-directed preferences, where a consumer is concerned about negative externalities of his own behaviour on others and displays altruistic behaviour. The authors sketch a couple of ideas and approaches and hint at many avenues for future research by departing from main-stream economic thinking.

Antoniou and Tsakiris (2016) propose a new argument for the superiority of quantities over prices in environmental regulation. In the main part of their paper they consider a single firm whose output is associated with emissions. It is assumed that demand and abatement costs are composed of a deterministic and a random part. Before the realisations of the random variables are revealed to the firm, the regulator and the firm may agree on an information disclosure agreement. If the firm accepts the agreement, the firm shares the revealed information about demand and abatement cost with the regulator, who then uses the updated information to select the socially optimal level of environmental regulation. It is shown that information disclosure, which increases social welfare, is more likely attained under an emission norm than under an emission tax.

Product certification reduces information asymmetry between producers and consumers with respect to product quality, like the environmental footprint of goods. Within a duopolistic market model, Das (2016) discusses the influence of (exogenous) horizontal differentiation between firms on equilibrium certification policy for two types of certifiers, a for-profit and a non-profit one. He shows that in the case of low horizontal differentiation and hence high competition between the firms, a for-profit certifier maximizes its profit by requesting a very high fee. This results in an inefficient market with one firm choosing the lowest quality and the other one the highest quality with certification. With a non-profit certifier both firms choose 
the highest quality and have their products certified irrespective of the level of horizontal differentiation. Correspondingly, a welfare analysis reveals that a non-profit certifier is weakly preferable from the point of view of a social planner.

In developing countries there are often mixed economies with oligopolistic competition between state owned and private firms. Such market systems can be observed in particular during the transition of centrally planned economic regimes to market economies. Ye and Zhao (2016) model such a mixed economy with duopolistic Cournot competition between a public firm and a private one. They show that in a mixed economy a tightening of environmental regulation does not necessarily reduce pollution, certain emission levels cannot be induced by emission taxes alone and the equivalence between environmental standards and taxes breaks down. An important player in the model is the public firm's CEO, whose choice between a public and a private career is assumed to be endogenous and dependent on environmental policy. The welfare rankings of policy instruments mainly depend on the induced career objectives. It is assumed that a CEO who strives for a private career puts a lower weight on social welfare and a higher weight on the public firm's profits than a CEO who strives for a public career.

Haan (2016) provides an explanation for voluntary overcompliance, implying that firms pollute less than required by environmental regulation and discusses the associated social welfare effects. The reasoning behind overcompliance is the attempt to reduce the stake of an environmental group in a future rent-seeking game. In an addendum, Haan discusses the relation of his contribution to the related literature.

\section{References}

Antoniou F, Tsakiris N (2016) On the informational superiority of quantities over prices in the presence of an externality. Environ Res Econ. doi:10.1007/s10640-015-9884-2

Buchholz W, Haupt A, Peters W (2016) Equity as a prerequisite for stability of cooperation on global public good provision. Environ Res Econ. doi:10.1007/s10640-015-9907-z

Caparrós A (2016) Bargaining and international environmental agreements. Environ Res Econ. doi:10.1007/ s10640-016-9999-0

Currarini S, Marchiori C, Tavoni A (2016) Network economics and the environment: insights and perspectives. Environ Res Econ. doi:10.1007/s10640-015-9953-6

Das S (2016) Certification under oligopolistic competition. Environ Res Econ. doi:10.1007/s10640-015-99033

Dasgupta P, Southerton D, Ulpha A, Ulph D (2016) Consumer behaviour with environmental and social externalities: implications for analysis and policy. Environ Res Econ. doi:10.1007/s10640-015-9911-3

Duscha V, Ehrhart K-M (2016) Incentives and effects of no-lose targets to include non-Annex I countries in global emissions reductions. Environ Res Econ. doi:10.1007/s10640-016-0015-5

Finus M, Rundshagen B (2015) Game theory and environmental and resource economics-In honour of Alfred Endres. Environ Res Econ 62:657-664

Haan M (2016) A rent-seeking model of voluntary overcompliance. Environ Res Econ. doi:10.1007/s10640015-9973-2

Karp L, Siddiqui S, Strand J (2016) Dynamic climate policy with both strategic and non-strategic agents: taxes versus quantities. Environ Res Econ. doi:10.1007/s10640-015-9901-5

Moulin H (1987) Egalitarian equivalent cost-sharing of a public good. Econometrica 55:963-977

Nieminen E, Kronbak LG, Lindroos M (2016) International agreements in the multispecies baltic sea fisheries. Environ Res Econ. doi:10.1007/s10640-015-9933-x

Rubinstein A (1982) Perfect equilibrium in a bargaining model. Econometrica 50:97-109

Vogt C (2016) Climate coalition formation when players are heterogeneous and inequality-averse. Environ Res Econ. doi:10.1007/s10640-016-0016-4

Ye G, Zhao J (2016) Environmental regulation in a mixed economy. Environ Res Econ. doi:10.1007/s10640015-9932-y 